\title{
EFFICIENT METAMATERIAL PARABOLIC OPTICAL TAP DESIGN
}

\author{
Noureddin M. Ibrahim \\ Department of Electronics \& Instrumentation Engineering Technology \\ Yanbu Industrial College, Saudi Arabia
}

\begin{abstract}
A metamaterial parabolic tap design is proposed and investigated; the tap has a metamaterial filling, it is designed for producing an efficient tapping where the subwavelength focusing exists. The design shows a high efficiency (power/physical dimensions) compared to a metamaterial rectangular tap design and to a natural material parabolic design. For comparison, the natural material parabolic design provides only $1 \%$ of the guided power while the output of the metamaterial parabolic design is $26 \%$. For the same length and depth, the metamaterial rectangular tap design produces $8 \%$. Moreover, it is noticed that the scattering around the tap is significantly low.
\end{abstract}

Keywords: Optical tap, metamaterial, perfect lensing.

\section{INTRODUCTION}

Optical taps are an essential element for optical networking and optical signal distribution [1], [2] and for on-board optical signal processing [3]-[6]. In optical fibers, tap designs take some forms like bending the fiber or removing part of its cladding [2]; in [1], a design was tested experimentally which has a tilted plate of thin aluminum inside the fiber to partially reflect propagating light. Although the later design is efficient compared to other tap designs they are all composed of natural materials, where the tapped beam cannot be easily and efficiently collimated, the same can be said about the integrated-optics taps. Metamaterials are considered for many microwave and optical applications like electromagnetic cloaking [7], harmonic generation [8], optical power splitters [9], optical tapping [10], and superlens imaging [11]. Metamaterials are defined as artificial materials, not available in nature, they are composed of particles from natural materials with sub-wavelength sizes [12].

The designs, materials, and arrangements of particles (meta-molecules) create a macroscopic effective refractive $\mathrm{n}=-\sqrt{ }\left(\varepsilon_{\mathrm{r}} \mu_{\mathrm{r}}\right)$ $(\mathrm{n}<0)$, where $\varepsilon_{\mathrm{r}}$ and $\mu_{\mathrm{r}}$ are the relative permittivity and relative permeability, respectively. For details about designs and implementations of metamaterials, readers are referred to [12]. Traditional designs of optical taps, which are fabricated from natural materials have many drawbacks including low efficiency and large sizes.

The subject of metamaterial was introduced theoretically by Veselago [13], he clarified many important electromagnetic phenomena of these artificial materials, like flat surface lensing and subwavelength focusing; although these materials do not exist in nature they are composed from natural materials. The material composition takes many shapes including split ring resonators and metallic wires [14], [15]. 
Pendry [16] introduced and investigated flat surface lens for perfect imaging, where both the relative permittivity $\left(\varepsilon_{\mathrm{r}}\right)$ and relative permeability $\left(\mu_{\mathrm{r}}\right)$ have the value of -1 . Another important feature of metamaterials is that Snell's law of refraction is still valid and applies at the metamaterial surface since the light beam inside the medium has a negative angle with the surface normal. In this case, the angles of incidence and refraction are always on the same side of the normal, as it is theoretically demonstrated and experimentally verified [17].

The characteristics of metamaterials in optical domain can be achieved using an arrangement and size of natural materials; for example, Shalaev, Cai, Chettiar, Yuan, Sarychev, Drachev, and Kildishev [18] used doubleperiodic array of pairs of parallel gold nanorods to obtain a negative refractive index of -0.3 at an infra-red wavelength of $1.5 \mu \mathrm{m}$; this is the feature the present tap design relies on, since metamaterial optical applications require nano-fabricated designs.

\section{THE TAP DESIGN}

In an attempt to improve the efficiency of optical tapping, two parameters are under consideration for this goal: the physical design of the tap and the type of material filling. For the physical design of the tap, it should be smooth enough and its configuration needs to be gradually changed for low scattering of light around the tap; the parabolic design is considered satisfying the requirement although not optimized. The metamaterial filling improves collimation and focus of the tapped light. A two-dimensional schematic diagram of the metamaterial tap design is depicted in Figure 1. The tap has a thickness $\mathrm{D}_{\mathrm{t}}$ inside the waveguide and length $\mathrm{W}_{\mathrm{t}}$ in $\mathrm{z}-$ direction. There is a pigtail of length $\mathrm{L}_{m}$ on the top of the tap. The tap and pigtail waveguide are filled with a perfect metamaterial (having a refractive index of -1 ). The design benefits from the feature of lensing with flat-surface metamaterial lens. The pigtail improves the collimation of light outside the waveguide when considering the proper dimension, leading to efficient coupling of tapped light to other waveguides or detectors; it is also noticed from the simulation the pigtail waveguide decreases scattered power noticeably in the substrate.

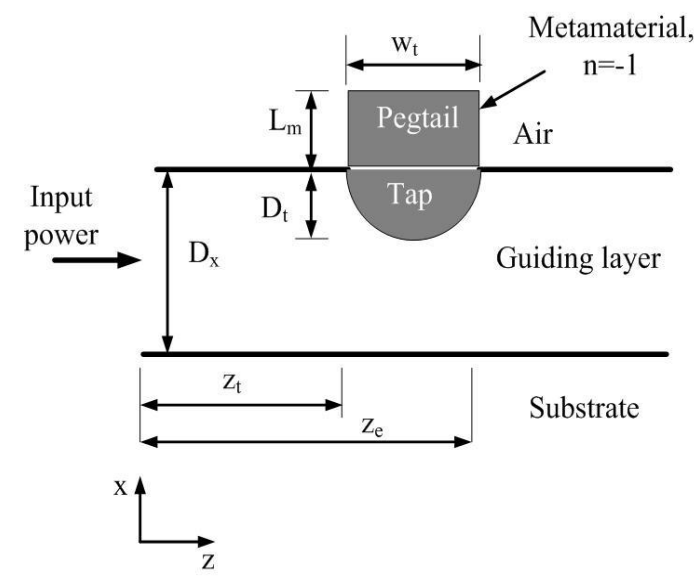

Fig.1. A schematic diagram showing the parabolic design of the metamaterial tap. The tap is investigated for its physical variables: the tap thickness $\mathrm{D}_{\mathrm{t}}$ inside the waveguide, the tap length $\mathrm{W}_{\mathrm{t}}$ in the propagation direction, and the pigtail length $\mathrm{L}_{\mathrm{m}}$ on the top of the tap. $\mathrm{D}_{\mathrm{x}}$ is the waveguide width in $\mathrm{x}$-direction.

The two-dimensional tap design is controlled by the parabola equation:

$x_{t}=a_{t} z^{2}+b_{t} z+c_{t}$

where the constants are defined by:

$a_{t}=D_{t} / z_{t}^{2}-z_{t} \times\left(z_{t}+z_{e}\right)+0.25 \times\left(z_{t}+z_{e}\right)^{2}$

$b_{t}=a_{t} \times\left(z_{t}+z_{e}\right)$

$c_{t}=D_{g}-D_{t}+0.25 \times a_{t} \times\left(z_{t}+z_{e}\right)^{2}$

Where $D_{t}, z_{t}$, and $z_{e}$ are, respectively, the thickness, the beginning, and the end of the tap, as shown in Figure 1; $\mathrm{W}_{\mathrm{t}}=\mathrm{Z}_{\mathrm{e}}-\mathrm{Z}_{\mathrm{t}}$.

\section{SIMULATION RESULTS}

Open-domain optical components cannot easily investigated and analyzed using closedform mathematical equations; instead, 
numerical methods can easily overcome this obstacle. One of these methods is the beam propagation method (BPM), where its fast Fourier transform version is adopted [19] for simulating the present tap design, although there are other versions of BPM for certain considerations [20]. The investigation is considered for two-dimensional $\mathrm{x}-\mathrm{z}$ space domain, where the direction of wave propagation inside the waveguide is $\mathrm{z}$, as shown from the schematic of Figure 1.

The operating wavelength $\lambda$ and waveguide thickness $\mathrm{D}_{\mathrm{g}}$ are fixed to $1.55 \mu \mathrm{m}$ and $18 \mu \mathrm{m}$, respectively; the waveguide refractive-index $n_{g}$, substrate refractive-index $\mathrm{n}_{s}$, and clad (air) refractive-index $\mathrm{n}_{\mathrm{c}}$ are, respectively, 1.44, 1.432 , and 1 . The calculation of propagating power is normalized to the input power at $\mathrm{z}=0$.

The three-dimensional plot of the wave propagating in the waveguide and the tapped portion of the wave are shown in Figure 2 (a), (b) and (c) (top) for three different tap designs, respectively: the parabolic metamaterial tap, the rectangular metamaterial tap, and the parabolic positiveindex material (PIM) tap. where the metamaterial taps have a refractive index $n=-$ 1, while the PIM tap is filled with a material having $\mathrm{n}=1.46\left(\mathrm{n}_{\mathrm{s}}+0.2\right)$. In the same figures 2 (a), (b), and (c), the two-dimensional plots labeled 1 show the signal distribution at $\mathrm{z}=1 \mu \mathrm{m}$, while the figures labeled 2 provide the plots at $\mathrm{z}_{\mathrm{t}}=350 \mu \mathrm{m}$, the beginning of the tap. The figures labeled 1 in (a), (b), and (c) are typical and the figures labeled 2 as well.

The figures labeled 3 in Figures (a), (b), and (c) are plotted at $\mathrm{z}=\mathrm{ze}=\mathrm{zt}+18 \mu \mathrm{m}$, i.e. at the end of each tap; they show the change happening in the signal because of the taps. The plot (a) 3 clearly indicates that the tapped portion of the signal is well separated from the main signal in the waveguide, leading to minimized power loss. The output of the rectangular metamaterial tap, as provided in (b) 3, shows that the tapped signal is very close to the main signal making it difficult to collimate into another waveguide or detector. The last tap design is the parabolic PIM tap with a refractive index of 1.46 . The tap can be classified as lowest efficiency tap compared to the parapolic and rectangular metamaterial taps.

The 3-dimentional plots at the top of (a) and (b) show the tap starting at $\mathrm{z}=350 \mu \mathrm{m}$, with a length $\mathrm{W}_{\mathrm{t}}=18 \mu \mathrm{m}$. The plot in the second row left shows the signal at $\mathrm{z}=1 \mu \mathrm{m}$, and the one on the right shows the signal at $z_{\mathrm{t}}=350 \mu \mathrm{m}$, the beginning of the metamaterial tap. The last row left shows the signal plot at the end of the tap, where there is a guided signal and an extracted (tapped) signal having only one narrow peak. The plot on the right in the last row shows the signal at the end of the waveguide, where the signal is no longer in the metamaterial. The metamaterial refractive-index is -1 and $\mathrm{L}_{\mathrm{m}}=18 \mu \mathrm{m}$. The tapped powers are respectively $26 \%, 6 \%$, and $0.89 \%$ of the total guided power in each waveguide.

The figure clarifies that the metamaterial lensing together with the parabolic design is effective and works constructively for efficient tapping from the parabolic metamaterial design making the tap superior to the other two designs. The parabolic design features curved boundary between the natural material waveguide and the metamaterial tap, leading to the decrease of the effect of the mismatch between the metamaterial and natural material.

The simulation is considered for all possible variable parameters including the material filling (natural material with $\mathrm{n}=1.54$ or metamaterial with $\mathrm{n}=-1$ ), the pigtail length $\mathrm{L}_{\mathrm{m}}$, the tap thickness $\mathrm{D}_{\mathrm{t}}$ inside the waveguide 

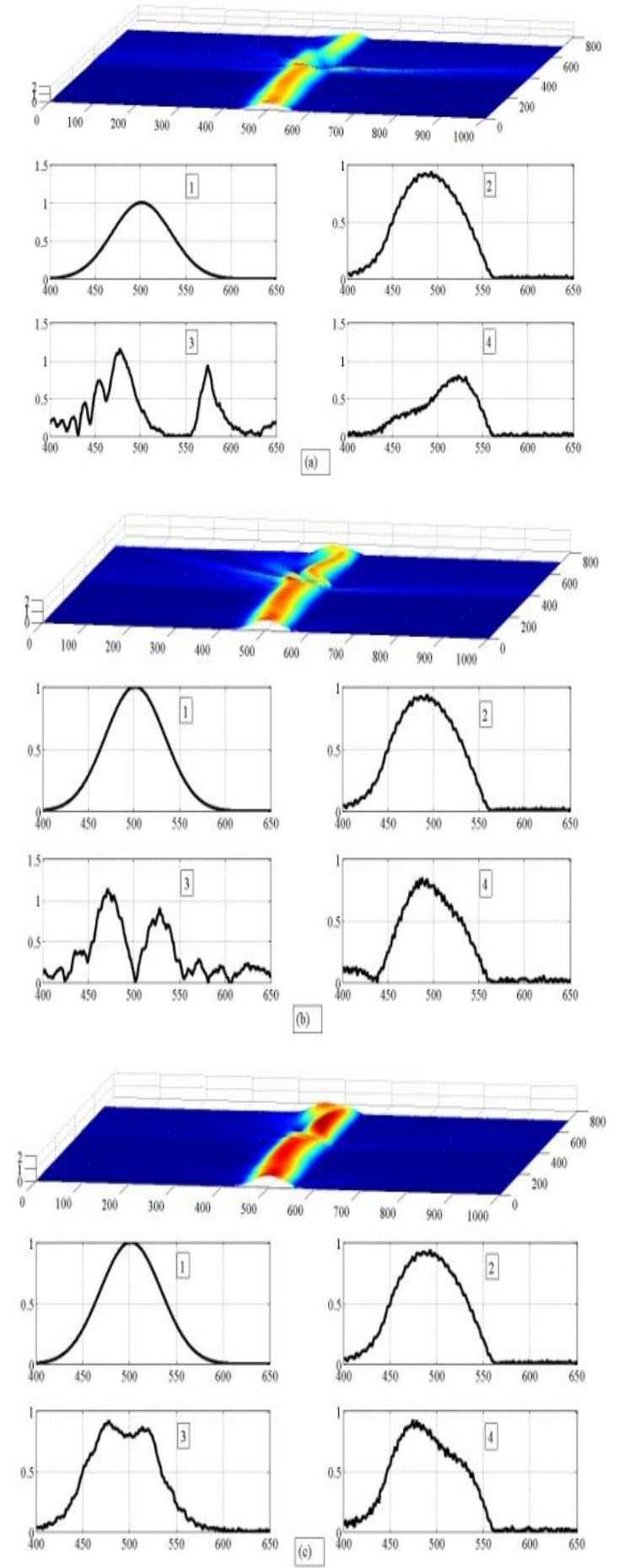

Fig.2. (a), (b) and (c) are plots characterizing the parabolic metamaterial tap, the rectangular metamaterial tap, and the parabolic PIM tap $\left(\mathrm{n}_{\mathrm{t}}=1.46\right)$, respectively.

and the tap length $\mathrm{W}_{\mathrm{t}}$ in the propagation direction $\mathrm{z}$; in this simulation, all materials are assumed lossless. The comparison is worked out between the two material types $(n=-1$, 1.532) for light tapping. In Figure 3, the plots show the superiority of the metamaterial tap

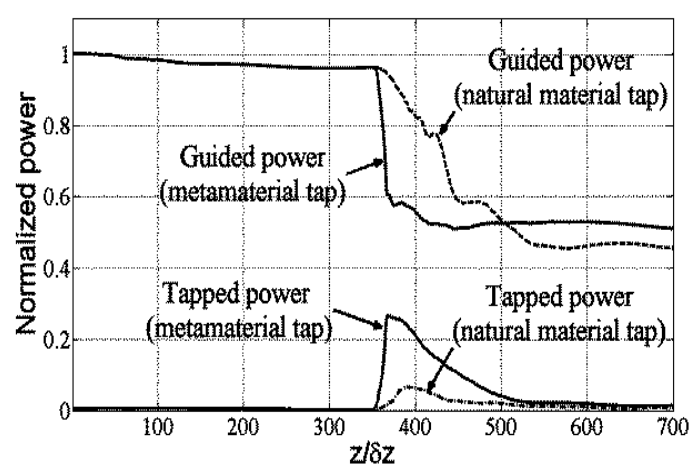

Fig.3. The guided powers in the waveguides and tapped powers from the taps with metamaterial $(n=-1)$ and natural material $(n=1.532)$ fillings.

over the one having a natural material filling. It can be noticed that the tapped power with metamaterial $(n=-1)$ filling has a sharp peak of 0.26 with a negligible displacement from the beginning of the tap while the tapped power from the one having a natural material $(\mathrm{n}=1.532)$ filling is only 0.06 and its peak has a noticeable displacement from the beginning of the tap. Roughly speaking, the tapping efficiency of the metamaterial tap compared to the natural material tap is almost 4.5 times higher.

The output of metamaterial tap shows its peak (0.26) with negligible displacement compared to the counterpart of the natural material tap (0.06). $\delta z$ is the propagation step size in $\mathrm{z}$-direction. $\mathrm{W}_{\mathrm{t}}=18 \mu \mathrm{m}, \mathrm{D}_{\mathrm{t}}=9 \mu \mathrm{m}$, and $\mathrm{L}_{\mathrm{m}}=18 \mu \mathrm{m}$.

The effect of the tap thickness $D_{t}$ inside the waveguide is studied to indicate that when $\mathrm{D}_{\mathrm{t}}=0$ (only the pigtail on the top of the waveguide with $\mathrm{L}_{\mathrm{m}}=\mathrm{D}_{\mathrm{x}}$ ) the tapped power has a peak of 0.02; this tapped power is generated from the evanescent modes outside the waveguide. The tapped power is clearly increasing with the increase of the tap thickness inside the waveguide.

The tap length $W_{t}$ in the propagation direction is another important parameter to investigate its effect on the tapped power. $\mathrm{W}_{\mathrm{t}}$ is allowed to vary, having the following values 
$0.5 \mathrm{D}_{\mathrm{x}}, \mathrm{D}_{\mathrm{x}}, 1.5 \mathrm{D}_{\mathrm{x}}$, and $2 \mathrm{D}_{\mathrm{x}}$. surprisingly, the highest peak value 0.265 is at $\mathrm{W}_{\mathrm{t}}=\mathrm{D}_{\mathrm{x}}$, while at $\mathrm{W}_{\mathrm{t}}=0.5 \mathrm{D}_{\mathrm{x}}, 1.5 \mathrm{D}_{\mathrm{x}}$, and $2 \mathrm{D}_{\mathrm{x}}$ the peaks are 0.12 , $0.23,0.204$, respectively. This means that the mathematical dependence of the peak power on $\mathrm{W}_{\mathrm{t}}$ is a relation having an optimum value as indicated in Figure 5. This relation is very interesting to qualitatively investigate for clarifying the effect of $W_{t}$ on the tap efficiency.

The coupling of propagating light to the tap is considered very high since the waveguide and the tap are directly coupled. As the tap length $\mathrm{W}_{\mathrm{t}}$ increases the tap becomes a waveguide running in parallel and adjacent to the original waveguide, focusing the guided light beam in $\mathrm{z}$ direction instead of $\mathrm{x}$ direction. The simulation was run for some other values of $\mathrm{D}_{\mathrm{x}}(10,12$, and $20 \mu \mathrm{m})$, the results provide the optima of the tapped powers in the three cases at $\mathrm{W}_{\mathrm{t}}=1.1 \mathrm{D}_{\mathrm{x}}, \mathrm{D}_{\mathrm{x}}$, and $\mathrm{D}_{\mathrm{x}}$, respectively. The numerical results are expanded as in Figure 6 for values of $W_{t} / \lambda$. The figure indicates that as $\mathrm{Wt} / \lambda$ increases, beyond the corresponding value of the optimum tapped power, the tap becomes a metamaterial waveguide, i.e. there is a metamaterial waveguide with a thickness $D_{t}$ on the top of a positive-index material (PIM) waveguide, its thickness is $\mathrm{D}_{\mathrm{x}}-\mathrm{D}_{\mathrm{t}}$.

The relation is nonlinear with a peak value of 0.26 at $\mathrm{W}_{\mathrm{t}}=\mathrm{D}_{\mathrm{x}}=18 \mu \mathrm{m} . \quad \mathrm{D}_{\mathrm{t}}=9 \mu \mathrm{m}$, and $\mathrm{L}_{\mathrm{m}}=18 \mu \mathrm{m}$.

The parabolic bottom of the tap (as in Figure 1) is then approximated by a straight line separating the metamaterial waveguide from the natural material waveguide. The light beam propagates inside the metamaterial waveguide using the superlensing feature of the perfect metamaterial $(\mathrm{n}=-1)$, as clarified in Figure 7 . In the figure, the three-dimensional plot is in the first row showing straight guidance with no tapping, the lengthy metamaterial section $(540 \mu \mathrm{m})$ works as

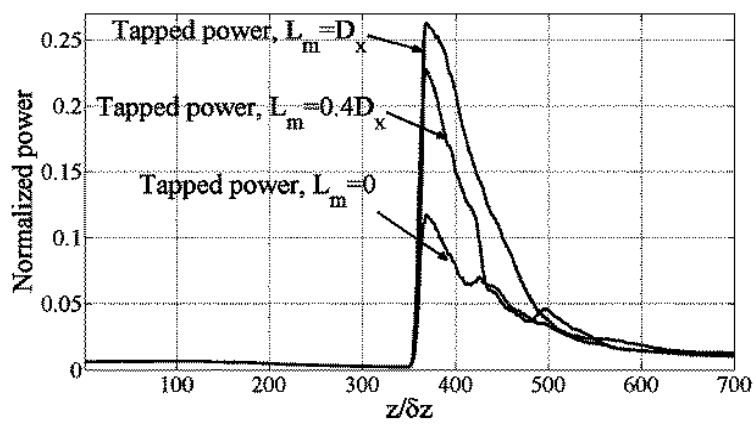

Fig. 4. The peaks of the tapped power corresponding to the tap thickness $\mathrm{D}_{\mathrm{t}}$ are: 0.26 at $\mathrm{D}_{\mathrm{t}}=0.3 \mathrm{D}_{\mathrm{x}}, 0.15$ at $\mathrm{D}_{\mathrm{t}}=0.2 \mathrm{D}_{\mathrm{x}}, 0.07$ at $\mathrm{D}_{\mathrm{t}}=0.1 \mathrm{D}_{\mathrm{x}}$, and 0.02 at $\mathrm{D}_{\mathrm{t}}=0 . \mathrm{W}_{\mathrm{t}}=18 \mu \mathrm{m}$.

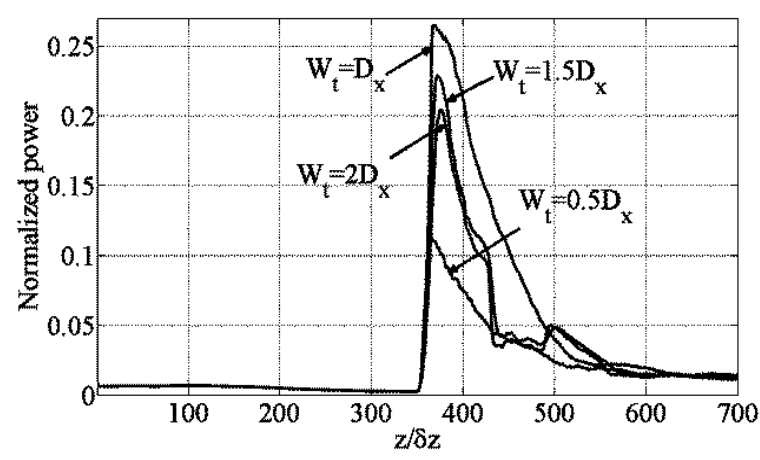

Figure 5. Tapped powers corresponding to the tap length in the propagation direction. They are 0.12 at $\mathrm{Wt}=0.5 \mathrm{Dx}, 0.265$ at $\mathrm{Wt}_{\mathrm{t}}=\mathrm{Dx}, 0.23$ at $\mathrm{Wt}=1.5 \mathrm{Dx}, 0.204$ at $\mathrm{Wt}=2 \mathrm{Dx}$. $\mathrm{Lm}=\mathrm{Dx}=18 \mu \mathrm{m}$.

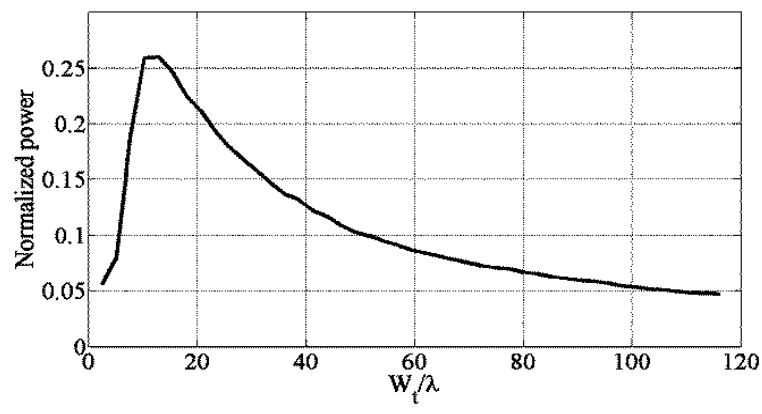

Fig.6. The relation between the tapped power and the tap length $\mathrm{W}_{\mathrm{t}} / \lambda$ in the propagation direction $\mathrm{z}$.

successive superlenses. On the left of the second row, there a plot of the input signal at $\mathrm{z}=1 \mu \mathrm{m}$, while on the right, there is a plot of the signal at the beginning of the metamaterial section $\left(\mathrm{z}=\mathrm{z}_{\mathrm{t}}=50 \mu \mathrm{m}\right)$. On the third row, the figure on the left clearly shows the effect of lensing characteristic of metamaterials where the spatial width of the signal $\left(\mathrm{z}=\mathrm{Z}_{\mathrm{e}}=590 \mu \mathrm{m}\right)$ is narrow compared with the one at the beginning of the metamaterial section. 

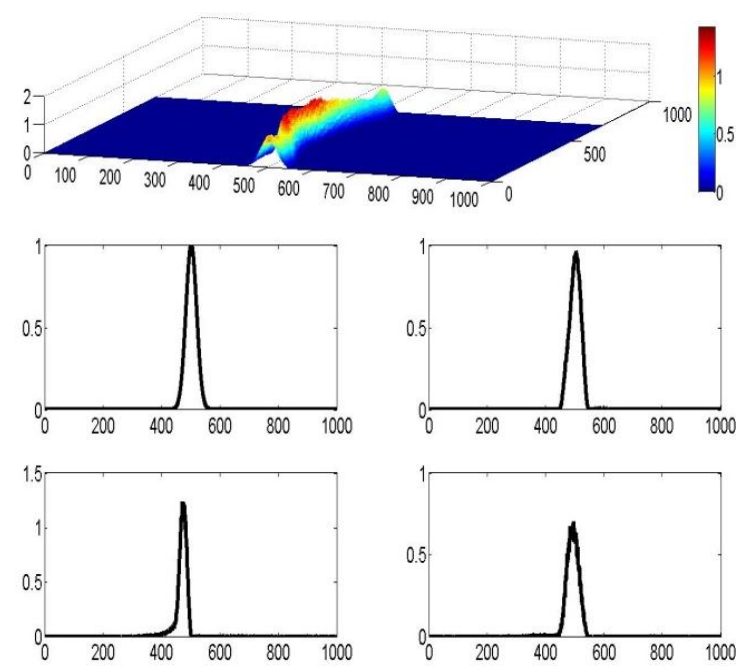

Figure 7 . When the tap length $\mathrm{W}_{\mathrm{t}}>\mathrm{D}_{\mathrm{t}}$, the tap works like a metamaterial waveguide featuring guiding light by focusing as indicated by the dark red in the three-dimensional plot. $2^{\text {nd }}$ row left, the plot of the input signal at $\mathrm{z}=1 \mu \mathrm{m}$ is provide, and the figure on the right of the same row shows the signal at $\mathrm{z}=\mathrm{z}_{\mathrm{e}}=50 \mu \mathrm{m}$, the beginning of the metamaterial. After propagation inside the metamaterial for $540 \mu \mathrm{m}$, the signal is plotted on the left of the $3^{\text {rd }}$ row, where it is narrow because of lensing characteristic of metamaterial. On the $3^{\text {rd }}$ row right, there is a plot of the signal after propagation in PIM for $110 \mu \mathrm{m}$, where it got wider because of the transverse expansion inside PIM.

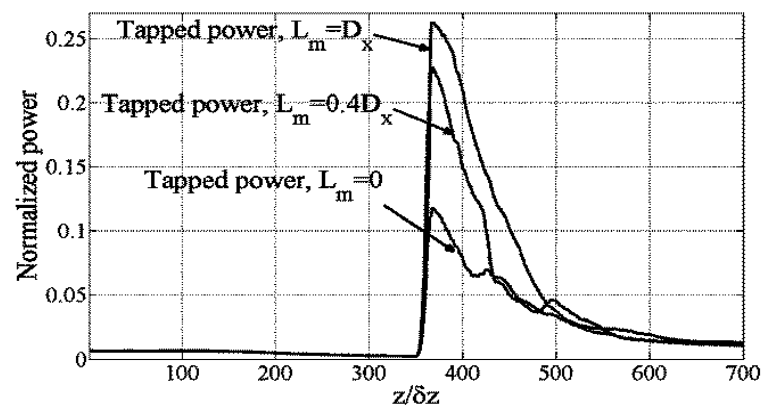

Figure 8. The peaks of the tapped power corresponding to the pigtail length $\mathrm{L}_{\mathrm{m}}$ are: 0.12 at $\mathrm{L}_{\mathrm{m}}=0,0.23$ at $\mathrm{L}_{\mathrm{m}}=0.2 \mathrm{D}_{\mathrm{x}}, 0.24$ at $\mathrm{L}_{\mathrm{m}}=0.4 \mathrm{D}_{\mathrm{x}}$, $\cong 0.26$ at $\mathrm{L}_{\mathrm{m}}=0.6 \mathrm{D}_{\mathrm{x}}, 0.8 \mathrm{D}_{\mathrm{x}}$, and $\mathrm{D}_{\mathrm{x}}$.

The last plot ( $3^{\text {rd }}$ row right) provides the signal plot at the end of the waveguide, the signal, after leaving the metamaterial signal, propagates in a PIM for $110 \mu \mathrm{m}$ subject to the natural characteristics of PIM, and the signal spatially gets expanded.

The pigtail length $\mathrm{L}_{\mathrm{m}}$ has its influential effect since it works like a flat perfect lens for the tapped light, which is collimated at a point outside the guiding region. When $\mathrm{L}_{\mathrm{m}}=0.6 \mathrm{D}_{\mathrm{x}}$, $0.8 \mathrm{D}_{\mathrm{x}}$, or $\mathrm{D}_{\mathrm{x}}$ the peak value is almost 0.26 while it decreases with the decrease of $\mathrm{L}_{\mathrm{m}}$, although the relation is noticeable an increasing nonlinear relation. When $\mathrm{L}_{\mathrm{m}}=\mathrm{D}_{\mathrm{x}}$, the power of the tapped beam is two times higher than the power when $\mathrm{L}_{\mathrm{m}}=0$.

\section{CONCLUSION}

In attempt to promote efficient tapping, a new optical tap design is introduced and investigated. The tap has a parabolic design and is filled with a metamaterial. The simulation results support the superiority of the design compared to PIM tap designs and to the rectangular metamaterial design. The combination of the metamaterial and parabolic design produce high quality anomalous tapping, including the subwavelength collimation of the tapped light, the negligible displacement between the tap location and tapped beam location.

The simulation results show that for the parabolic design with positive-refractive-index ( $\mathrm{n}=1.532$ ), the output is 0.01 of the guided power while the output from the same design, with a metamaterial $(\mathrm{n}=-1)$ filling, is 0.26 For the same length and thickness, the rectangular design, with a metamaterial filling, extracts only 0.08 . Moreover, the investigation of the introduced design is able to collimate the tapped power in a subwavelength dimension, as it is a feature of the metamaterial perfect lens $(\mathrm{n}=-1)$.

Scattering near tap location in integratedoptics and optical fibers is a challenge, the present design could considerably decrease the scattering due to the parabolic design and the metamaterial the tap is composed of.

\section{REFERENCES}

[1] Ibrahim, N., and Fattah, I., "Narrow-beam aluminum-mirrored fiber optical-taps with controllable tapped power," IEEE Journal of Selected Topics in Quantum Electronics, Vol 2 (2), pp. 221-225, 1996. 
[2] Iqbal, M., Fathallah, H., and Belhadj, N., “Tapping optical fiber: Methods and precautions," Proceedings of the 8th Coonference on High Capacity Optical Networks and Enabling Technologies (HONET), December, Riyadh, Saudi Arabia, pp. 164-168, 2011.

[3] Van Eck, T., Ticknor, A., Lytel, R., and Lipscomb, G., "Complementary optical tap fabricated in an electro-optic polymer waveguide," Applied Physics Letters, Vol. 58 (15), pp. 15881590, 2001.

[4] Stinger, V., and Beyette, F., "Silicon CMOS based vertical multimode interference optical taps," Proceedings of SPIE, Wave Optics and VLSI Photonic Devices for Information Processing, Pierre Ambs, P., and F. Beyette (Eds.), pp. 145-151, 2001.

[5] Stinger, V., and Beyette, F., "Design and analysis of an optical waveguide tap for silicon CMOS circuits," Journal of Lightwave Technology, Vol. 20 (2), pp. 277-284, 2002.

[6] Chen, Z., "Development of optical tap for planar lightwave circuits and intra-chip optical interconnect using ion implantation," a master thesis, University of Pittsburg, 2006.

[7] Kildishev, A., Cai1, W., Chettiar, U., and Shalaev, V., "Transformation optics: approaching broadband electromagnetic cloaking," New Journal of Physics 10 , pp. 115029-115041, 2008.

[8] Feth, N., Linden, S., Klein, M., Decker, M., Niesler, F., Zeng, Y., Hoyer, W., Liu, J., Koch, S., Moloney, J., and Wegener, M., "Secondharmonic generation from complementary splitring resonators," Optics Letters, Vol. 33, No. 17, Sept. 1, pp. 1975-1977, 2008.

[9] Ibrahim, N., "Characterization of optical negative-index-material splitter," The 3rd IEEE International Conference on Information \& Communication Technologies: from Theory to Applications, ICTTA'08, April, Damascus, Syria, pp. 1884-1887, 2008

[10] Ibrahim, N., "Light tapping using metamaterials: 2-D simulation," The Sixth International Conference on wireless and Optical communications Networks WOCN2009, Cairo, Egypt, pp. 222-225 April, 2009.

[11] I. Ehrenberg, S. Sarma, and B.-I. Wu, "A threedimensional self-supporting low loss microwave lens with a negative refractive index," J. of
Applied Physics, Vol. 112, pp. 073114-073117, 2012.

[12] (a) Caloz, C., and Itoh, T., Electromagnetic metamaterials: transmission line theory and microwave applications, the Engineering Approach, John Wiley \& Sons, Inc., 2006. (b) Cai, W. and Shalaev, V., Optical metamaterials: Fundamentals and applications, Springer Science+Business Media, LLC, 2010.

[13] Veselago, V., "The electrodynamics of substances with simultaneously negative values of $\varepsilon$ and $\mu$," Soviet Physics, Vol. 10 (4), pp. 509-514, 1968.

[14] Linden, S., Enkrich, C., Dolling, G., Klein, M., Zhou, J., Koschny, T., Soukoulis, C., Burger, S., Schmidt, F., and Wegener, M., "Photonic metamaterials: Magnetism at optical frequencies," IEEE J. of Selected Topics in Quantum Electronics, Vol. 12 (6), pp. 2-10, 2006.

[15] Klar, T., and Kildishev, A., Drachev, V., and Shalaev, V., "Negative-index metamaterials: going optical. IEEE J. of Selected Topics in Quantum Electronics, Vol. 12 (6), pp. 1106-1115, 2006.

[16] Pendry, J., "Negative refraction makes a perfect lens," Physical Review Letters, Vol. 85, pp. 39663969, 2000.

[17] Houck, A., Brock, J., and Chuang, I., "Experimental confirmation of a lefthanded material that obeys Snell's law," Phys. Review Letters, Vol. 90 (13), Paper no. 137401, pp. 1-4, 2003.

[18] Shalaev, V. and Cai, W., Chettiar, U., Yuan, H.K., Sarychev, A., Drachev, V., and Kildishev, A., "Negative index of refraction in optical metamaterials," Optics Letters, Vol. 30 (24), pp. 3356-3358, 2005.

[19] Feit M., and Fleck, J., "Light propagation in graded-index optical fibers," Applied Optics, Vol. 17, pp. 3990-3998, 1978.

[20] Obayya, S., Computational photonics, John Wiley \& Sons, 2011. 


\title{
تصميم كفء بشكل القطع المكافئ لِنَقَر ماوراء المادة الضوئي
}

\author{
نور الدين محمد إبر اهيم \\ قسم تقنية هندسة الإلكترونيات و القياس، كلية ينبع الصناعية \\ المملكة العربية السعودية
}

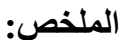

تم اقتراح تصميم بشكل القطع المكافئ لنقر ماوراء المادة الضوئي وكذلك نم فحصه علميا؛ حيث أن ملؤه من مادة افتراضية أو ماوراء المادة، لقد تم تصميمه من أجل استخر اج جزء من الضوء المار في شعيرة ضوئية بطريقة عالية الكفاءة حيث تركيز الضوء يصل الي مساحة أبعادها جزء من الطول الموجي للضوء المستخرج. وقد أظهر التصميم كفاءة عالية (القدرةالأبعاد الطبيعية) مقارنة بتصميم نقر ضوئي من ماوراء المادة ولكنه بشكل مستطيل ومقارنة أيضا لذات التصميم بشكل القطع المكافئ ولكنه من مو اد طبيعية منو افرة. للمقارنة، فإن التصميم علي شكل القطع المكافئ ذي المو اد الطبيعية بساعد علي استقطاع 1\% فقط من القدرة الضوئية المارة في الثعيرة الضوئية بينما يساعد ذات التصميم ولكنه من ماوراء المادة علي الحصول علي 26\% من القدرة الضوئية المارة في الثعيرة الضوئية. وبالمقارنة مع النقر ذي الثنكل المستطيل ومكون من ذات ماور اء المادة فإن التصميم المستطيل بياعد علي توفير 8\% فقط من القدرة الضوئية المارة في الثعيرة الضوئية. و أكثر من ذللك، فقد لوحظ أن تشتت الضوء حول تصميم النقر ذي شكل القطع المكافئ من ماوراء المادة قليل بشكل ملحوظ. 